Original Research Article

\title{
A prospective observational study of prescription pattern in a tertiary care teaching hospital of Jharkhand
}

\author{
Abha Kumari, Keshav Kumar*, Manju Gari, Kumari Pallavi, Subhankar Choudhury
}

Department of Pharmacology and Therapeutics, Rajendra Institute of Medical Sciences, Ranchi, Jharkhand, India

Received: 16 September 2019

Revised: 18 October 2019

Accepted: 25 October 2019

*Correspondence to:

Dr. Keshav Kumar,

Email: drkeshav912@gmail.com

Copyright: (C) the author(s), publisher and licensee Medip Academy. This is an openaccess article distributed under the terms of the Creative Commons Attribution NonCommercial License, which permits unrestricted noncommercial use, distribution, and reproduction in any medium, provided the original work is properly cited.

\begin{abstract}
Background: Prescription error and irrational prescribing are the avoidable problems imposed on health care delivery system from prescriber side which must be addressed. Periodic prescription audit helps to curtail the error and irrational prescribing.

Methods: A prospective observational study was conducted on patients visiting various Outpatient Department of RIMS, Ranchi, Jharkhand on all working days at 11:00 AM to 12:00 PM from 1 August 2018 to 31 July 2019. Various aspects of collected prescriptions were analyzed by using World Health Organization (WHO) prescribing indicators.

Results: In this study, out of 700 prescriptions collected, 76 were excluded. Out of total 624 patients analyzed, $382(61.28 \%)$ were male and $242(38.72 \%)$ were female. $48(7.69 \%)$ patients belonged to $\leq 18,464(74.36 \%)$ to $19-64$ and 112 $(17.95 \%)$ to $\geq 65$ years of age group. Tablet $(71 \%)$ was the most common dosage form. None of prescriptions were having registration number of the doctor. $242(38.78 \%)$ prescriptions did not have a diagnosis duly written. The total no. of drugs prescribed in 624 prescriptions was 2176 . Only $32(5.13 \%)$ prescriptions were found to have medicines prescribed in block letters. Antibiotics (29\%) were the most common class of drugs prescribed. Average number of drugs per prescription was 3.47. Only $48(2.20 \%)$ drugs were prescribed by their generic name while total of injectables prescribed were 102 (4.68\%). Total number of drugs from NLEM was 848 (38.97\%). 196 (9.00\%) drugs were fixed-dose combination.

Conclusions: In our study, we found deficiencies in various parts of prescriptions. Prescribing pattern was not in accordance with WHO recommendation for prescribing practice.
\end{abstract}

Keywords: Prescription error, Irrational prescribing, Prescribing indicators, Prescription audit

\section{INTRODUCTION}

A prescription is an instruction from a prescriber to a dispenser and is considered to be a medico-legal document that must be written legibly, accurately and completely. ${ }^{1}$ Prescription error accounts for major proportion of preventable medication error which many a time takes big toll even in the form of death of patient. The prescription error may occur when a physician prescribes without considering patient's clinical status, age and body weight, co-morbid conditions, drug- drug interaction and allergy status; writes drug's name using abbreviation or non-standard notation and does not write prescription as per the most recent recommendation. According to the National Coordinating Council for Medication Error Reporting and Prevention (NCC
MERP), in $15 \%$ of the medication error reports, the error occurred because of illegible handwriting, problems with leading and trailing zeroes, misinterpreted abbreviations, and incomplete medication orders. ${ }^{2}$

As per World Health Organization (WHO), rational use of drug requires that the patients receive medicines appropriate to their clinical needs, in doses that meet their own individual requirements for an adequate period of time, at the lowest cost to them and their community. In other words, irrational prescribing can be described as medically inappropriate and economically ineffective use of pharmaceuticals. It is commonly observed practice seen in both developed and developing countries, with enormous costs from the perspectives of the scarce resources and clinical consequences. It may occur in the 
form misuse, overuse, polypharmacy, adverse drug events or drug-drug interaction. Worldwide more than $50 \%$ of all medicines are prescribed, dispensed or sold inappropriately, while $50 \%$ of patients fail to take them correctly. ${ }^{3}$

Irrational prescribing is a global problem. ${ }^{4}$ Periodic audit of prescriptions is essential to improve drug utilization pattern and reduce irrational prescribing. ${ }^{5}$ WHO document "how to investigate drug use in health facilities" is a valuable document used to assess drug use in both government and private health facilities. ${ }^{6}$ Regarding prescribing pattern, little current data are available in the given geographical areas. So to conduct the present study was imperative.

\section{Aim}

The aim of present study was to conduct a prescription audit to assess legibility, errors in different parts of prescription and the current prescribing pattern using WHO prescribing indicators.

\section{METHODS}

This was a prospective observational study. The study population consisted of patients who visited various outdoor patient departments (OPDs) of the hospital between 11:00AM to 12PM on working days irrespective of their age, sex and disease. A total of 700 prescription slips (photo copies) were collected from various OPDs of Rajendra Institute of Medical Sciences (RIMS), Ranchi, Jharkhand on all working days at 11:00AM to 12:00PM from 1 August 2018 to 31 July 2019. Data was obtained from the prescription slips.

Prescriptions were analyzed for their legibility. Legibility was assessed by observing whether all parts of prescription were clear for reading with or without effort. Prescriptions were categorized as- legible if they could be read without the help of other health care professionals (HCPs), legible with effort if they could be read with the help of other HCPs and illegible if they could not be read even with the help of other HCPs.

Out of 700 prescription collected, fifty six prescriptions were excluded because of being illegible and twenty prescriptions were excluded from the study because they were either follow-up prescription or comprised of investigational advice or referral advice.

A total of 624 prescriptions were analyzed. The patients were classified as per age and sex. Then we analyzed prescribing errors in different parts of prescriptions and prescribing pattern using WHO prescribing indicators. For assessing prescribing pattern we looked for number of prescriptions from various OPDs, common dosage forms, classes of drugs prescribed. Besides these, we also looked for fixed-dose combinations (FDCs).

\section{Parts of prescription}

Different parts of prescriptions consist of superscription which include name, age, sex and address of the patient; date of writing prescription and the diagnosis; inscription or the body of the prescription which contains name and the amount or strength of the drug to be dispensed or name and strength of each ingredient to be compounded; subscription which is instruction to the pharmacist; transcription which is direction to the patient regarding how to take the medication; signature of prescriber.

For assessing prescribing pattern we used WHO core drug use (prescribing) indicators, i.e., average number of drugs per encounter, percentage of drugs prescribed by generic name, percentage of encounters with an antibiotic prescribed, percentage of encounters with an injection prescribed and percentage of drugs prescribed from essential drugs list or formulary.

Data obtained from prescription slips was analyzed using Microsoft office Excel 2007. Data were presented in text and tabular forms as well as in the form of pie and bar charts.

\section{RESULTS}

Out of 700 prescription collected, $455 \quad(65 \%)$ prescriptions were legible, $189(27 \%)$ were legible with effort and $56(8 \%)$ were illegible (Figure 1).

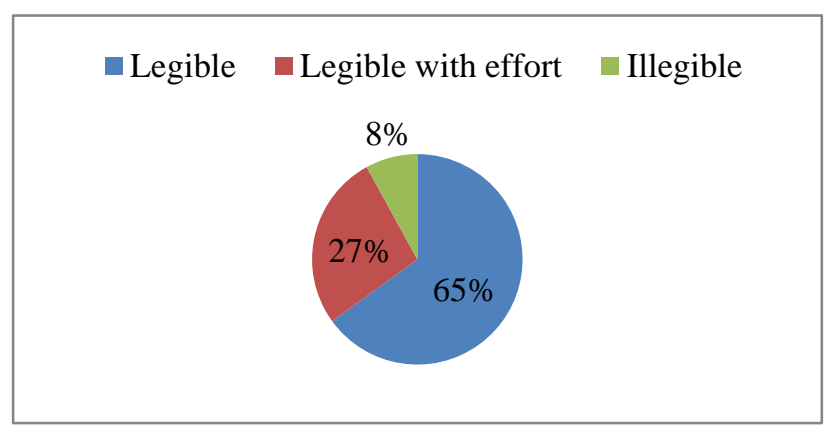

Figure 1: Legibility.

Table 1: Age and sex-wise distribution of patients.

\begin{tabular}{|lcl|}
\hline \multicolumn{2}{|c|}{ Number } & $\%$ \\
\hline Sex & & \\
\hline Male & 382 & 61.28 \\
\hline Female & 242 & 38.72 \\
\hline Age groups (in years) & \\
\hline$\leq 18$ & 48 & 7.69 \\
\hline $19-64$ & 464 & 74.36 \\
\hline$\geq 65$ & 112 & 17.95 \\
\hline
\end{tabular}

Out of total 624 patients analyzed, $382(61.28 \%)$ were male and $242(38.72 \%)$ were female. $48(7.69 \%)$ patients belonged to $\leq 18$ years, $464(74.36 \%)$ patients to $19-64$ 
years and $112(17.95 \%)$ patients to $\geq 65$ years of age group (Table 1).

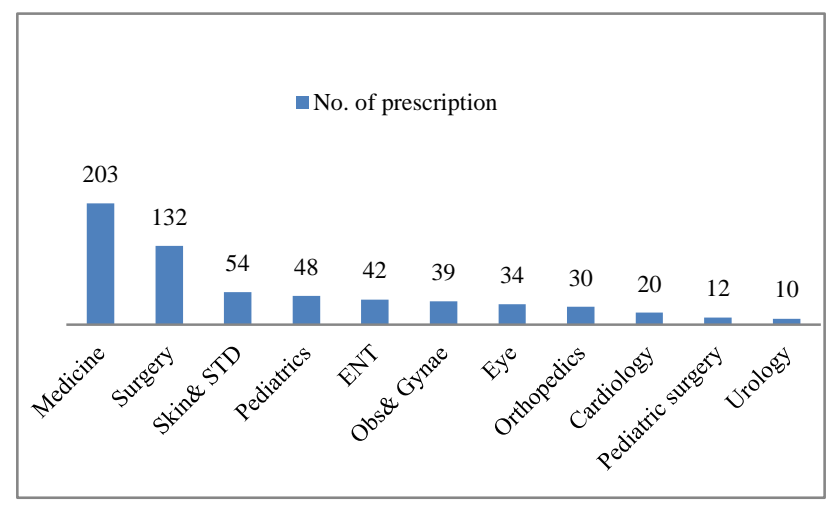

Figure 2: Prescriptions collected from various OPDs.

The number of prescriptions collected from various OPDs was as depicted in Figure 2. The highest number of prescription (203) was collected from medicine OPDs followed by 132 from surgery, 54 from skin and sexually transmitted disease, 48 from pediatric, 42 from ENT, 39 from obstetrics and gynaecology, 34 from eye, 30 from orthopedic, 20 from cardiology, 12 from pediatric surgery and 10 (the lowest one) from urology OPDs.

\section{Table 2: Assessment of different parts of} prescriptions.

\begin{tabular}{|ll|}
\hline Parameter & N (\%) \\
\hline Prescriptions having no diagnosis & $242(38.78)$ \\
\hline $\begin{array}{l}\text { Prescriptions having medicines } \\
\text { prescribed in block letter }\end{array}$ & $32(5.13)$ \\
\hline Other forms of prescribing errors & $126(20.19)$ \\
\hline
\end{tabular}

$\square$ Tablet $\square$ capsule $\square$ Topical $\square$ Syrup $\square$ Injectable

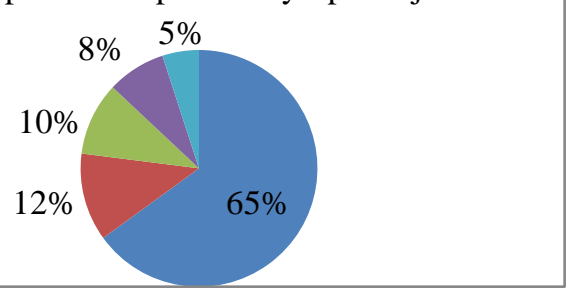

Figure 3: Dosage forms.

All of the 624 prescriptions contained name, age, sex and weight of the patients as well as registration number as patient's identity but none of the prescriptions had any mention of religion, occupation and socio-economic status of the patients. None of the prescriptions had registration no. of doctor mentioned. 242 (38.78\%) prescriptions did not have a diagnosis duly written. 126 (20.19\%) prescriptions were having prescribing errors in the forms of- dosage forms not mentioned, use of abbreviation (e.g., PCM for paracetamol) or non-standard notation for generic name, dose or strength not mentioned, frequency and duration of intake of drugs not mentioned. Only $32(5.13 \%)$ prescriptions were found to have medicines prescribed in block letters. All the prescriptions were having signature of prescriber (Table 2).

The most common dosage form was tablet (65\%) followed by capsule (12\%), topical $(10 \%)$, syrup $(8 \%)$ and injectables (5\%) (Figure 3).

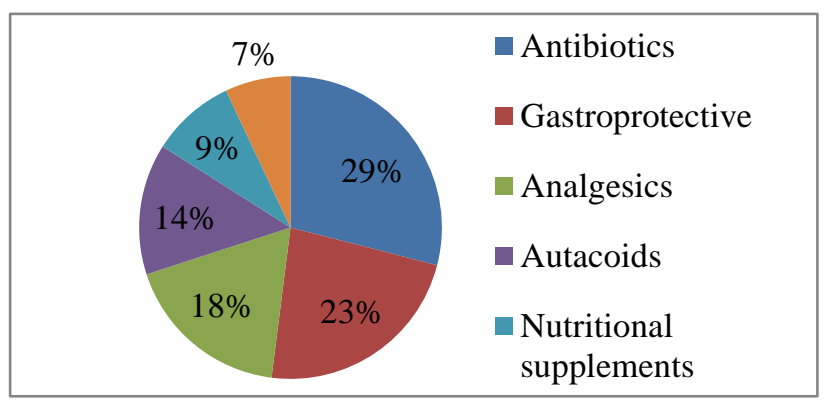

Figure 4: Classes of drugs.

Antibiotics (29\%) were the most common class of drugs prescribed followed by gastroprotective (23\%), analgesics (18\%), autacoids (14\%), nutritional supplements (9\%) and others (7\%) (Figure 4). Among the antibiotics amoxicillin was the most common. Pantoprazole was the most common gastroprotective. Among analgesics paracetamol was the most common. Levocetrizine was the most common autacoids while iron preparation was the most common nutritional supplement.

Table 3: Number of drugs per prescription and percentage.

\begin{tabular}{|lll|}
\hline $\begin{array}{l}\text { No. of drugs per } \\
\text { prescription }\end{array}$ & $\begin{array}{l}\text { No. of } \\
\text { prescriptions }\end{array}$ & $\%$ \\
\hline $\mathbf{1}$ & 34 & 0.05 \\
\hline $\mathbf{2}$ & 116 & 18.59 \\
\hline $\mathbf{3}$ & 204 & 32.69 \\
\hline $\mathbf{4}$ & 132 & 21.15 \\
\hline $\mathbf{5}$ & 94 & 15.06 \\
\hline $\mathbf{6}$ & 24 & 0.04 \\
\hline $\mathbf{7}$ & 10 & 0.02 \\
\hline $\mathbf{8}$ & 6 & 0.01 \\
\hline $\mathbf{9}$ & 2 & 0.003 \\
\hline $\mathbf{1 0}$ & 2 & 0.003 \\
\hline & Total= 624 \\
\hline
\end{tabular}

Number of drugs per prescription was ranging from 1 to 10 and 3 being the most common figure seen in 204 prescriptions while 9 and 10 being the least common figure seen in each of 2 prescriptions (Table 3 ).

The total number of drugs prescribed was 2176 , so the average number of drugs per prescription was 3.47. Only $48(2.20 \%)$ drugs were prescribed by their generic name 
while total of injectables prescribed were 102 (4.68\%). Total number of drugs from National List of Essential Medicines (NLEM) were 848 (38.97\%). 196 (9.00\%) drugs were fixed-dose combination (FDCs), pantoprazole-domperidone being the most common (Table 4).

\section{Table 4: WHO core drug use (prescribing practice) indicators.}

\begin{tabular}{|ll|}
\hline $\begin{array}{l}\text { Indicators } \\
\text { Average number of drugs per } \\
\text { encounter }\end{array}$ & N $(\%)$ \\
\hline $\begin{array}{l}\text { Percentage of drugs prescribed by } \\
\text { generic name }\end{array}$ & $48(2.47$ \\
\hline $\begin{array}{l}\text { Percentage of encounters with an } \\
\text { antibiotic prescribed }\end{array}$ & $181(29.00)$ \\
\hline $\begin{array}{l}\text { Percentage of encounters with an } \\
\text { injection prescribed }\end{array}$ & $102(4.68)$ \\
\hline $\begin{array}{l}\text { Percentage of drugs prescribed from } \\
\text { NLEM }\end{array}$ & $848(38.97)$ \\
\hline Number of FDCs prescribed & $196(9.00)$ \\
\hline
\end{tabular}

Figure 5 shows comparison of important findings of the present study with WHO recommendation. The average no of drugs per prescription, percentage of drugs prescribed by generic name, percentage of prescriptions with antibiotics, percentage of encounters with an injection and percentage of drugs prescribed from NLEM in the present study were $3.47,2.20 \%, 29.00 \%, 5.00 \%$ and 38.97 against WHO recommendation of $1.8 \%, 100 \%$, $30 \%, 10 \%$ and $100 \%$ respectively.

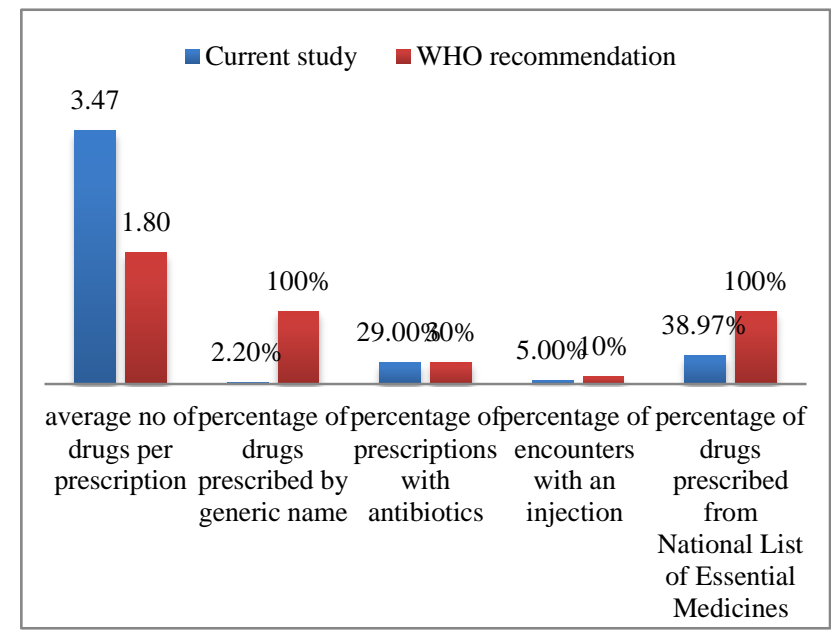

Figure 5: Comparison of important findings of current study with WHO recommendation.

\section{DISCUSSION}

In our study, we found 56 prescriptions were illegibly written. Legibility is one of the common avoidable problems associated with prescription writing as seen in another study conducted by Raj et al. ${ }^{1}$ The prescribing errors which we found in the present study were consistent findings as seen in other study conducted by Raj et al.

In the study, the average number of drugs per encounter was 3.47. As per WHO the average number of drugs per encounter should be 1.6-1.8. Although, 3.47 is not the figure to declare polypharmacy but many of individual prescriptions clearly showed polypharmacy. Similar results have also been reported by various studies from other states of India like Tamil Nadu, Madhya Pradesh, Uttar Pradesh and West Bengal (5, 2.8, 3.1 and 3.05 respectively). ${ }^{7-9,11}$ Average number of drugs per prescription reported from China and Bangladesh was 2.04 and 1.44 , respectively. ${ }^{12,13}$ In this study, only $2.20 \%$ drugs were found to be prescribed by generic names which is much less than those reported from other states of India like Tamil Nadu, Madhya Pradesh, Uttar Pradesh, Karnataka, and West $\operatorname{Bengal}(62 \%, 48.5 \%$, $27.1 \%, 16 \%$ and $8 \%$ respectively ${ }^{7-11}$ Studies from China and Nigeria reported 69.2 and $42.7 \%$ generic prescribing. $^{12,14}$ WHO recommends $100 \%$ generic prescribing.

In the present study, percentage of prescriptions with an antibiotic was $29 \%$ which was similar to result of a study conducted in Kolkata (30\% antibiotics) but fortunately lesser than that reported from other states of India like Tamil Nadu, Madhya Pradesh and Uttar Pradesh (60.9\%, $55 \%$ and $39.9 \%$ respectively). ${ }^{7-9}$ Studies from China, Nigeria and Pakistan shows $78 \%, 75 \%$ and $38.15 \%$ respectively. ${ }^{12,14,15}$ WHO recommends antibiotics should be prescribed in $<30 \%$ of prescriptions.

Percentage of prescriptions with injectable in this study was $4.68 \%$ which is in accordance with WHO recommendation of $<10 \%$ prescription with injectables. Studies from other states like Tamil Nadu and Madhya Pradesh reported $13.6 \%$ and $8.12 \%$ prescriptions with injectables. ${ }^{7,8}$ Studies from the countries such as China, Nigeria and Pakistan reported respectively $22.63 \%, 4 \%$ and $73 \%$ of prescriptions with injectables. ${ }^{12,14,15}$

The percentage of drugs prescribed from NLEM in the present study was 38.97 which were much lesser than WHO recommendation of $100 \%$ to be prescribed from NLEM. Studies from Tamil Nadu, Madhya Pradesh, and West Bengal reported respectively $37.3 \%, 66.9 \%$ and $29.38 \%$ drugs from NLEM. ${ }^{7,8,11}$

The place of present study, being a tertiary care hospital obviously has overload of patients. Doctors are compelled to tackle patients as much as possible. Prescribing in block letters takes longer time than doing in running hand. A very low doctor-patient ratio appears to be the most important hurdle to the success.

\section{CONCLUSION}

In spite of continuous effort by health agencies concerned with prescribing errors (e.g., NCC MERP) illegibility and 
prescribing errors are still persisting. Lack of mentions about diagnosis and dosage forms; and inability to write generic name in block letter were the most common prescribing errors. There was also a polypharmacy in drug use. Generic prescribing was much less than WHO recommendation. The number of antibiotics per prescription and the number of injection per prescription was as per WHO recommendation. Further, the number of drugs from NLEM was not as per WHO recommendation. Periodic prescription audit should be one of the strategies to check deficiencies in prescriptions and to improve current prescribing pattern.

Funding: No funding sources

Conflict of interest: None declared

Ethical approval: The study was approved by the Institutional Ethics Committee

\section{REFERENCES}

1. Raj P, Choudhury S, Kundu S, Patel S, Sidar B. Study of prescription pattern in a tertiary care hospital in Chhattisgarh, India: an observational study. Int J Basic Clin Pharmacol. 2018;7:598-602.

2. Meyer TA. Improving the quality of the order-writing process for inpatient orders and outpatient prescriptions. Am J Health-System Pharm. 2000;57(S4):18-2.

3. World Health Organization. Promoting rational use of medicines: core components. Policy Perspectives on Medicines. Geneva: World Health Organization; 2002.

4. Kumari K, Kumar P. Study of drug prescribing pattern in a Tertiary Care Hospital in Jharkhand. IJBR. 2017;8(2):85-8.

5. Mishra P, Suman S, Keshri UP, Mishra PK, Kumari K. The use of ATC/DDD WHO 2016 and prescription audit study in the dermatology OPD of a tertiary care hospital in Jharkhand, India. Int J Basic Clin Pharmacol. 2018;7:2409-13.

6. World Health Organization. How to investigate drug use in health use indicators. WHO/DAP/93.1. Available at: https://apps.who.int/medicinedocs/pdf/ s2289e/s2289e.pdf. Accessed on 27 August 2019.
7. Gopalakrishnan S, Ganeshkumar P, Katta A. Assessment of prescribing practices among urban and rural general practitioners in Tamil Nadu. Indian $\mathbf{J}$ Pharmacol. 2013;45(3):252-7.

8. Bhartiy SS, Shinde M, Nandeshwar S, Tiwari SC. Pattern of prescribing practices in the Madhya Pradesh, India. Kathmandu Univ Med J. 2008;6(1):55-9.

9. Kumari R, Idris MZ, Bhushan V, Khanna A, Agrawal $\mathrm{M}$, Singh SK. Assessment of prescription pattern at the public health facilities of Lucknow District. Indian J Pharmacol. 2008;40(6):243-7.

10. Patil KK. Prescribing pattern among intern at the rural health centre of the medical college, Manipal. IJCM. 2004;13(3):129-9.

11. Mandal P, Mondal S, Das A, Rahaman M, Nandy M, Jana S. Evaluation of prescribing indicators in prescriptions of private practitioners in Kolkata, India. Int J Basic Clin Pharmacol. 2015;4:919-23.

12. Jun Z, Linyun L, Che Z, Yuanrong Y, Fengxai G, Heng Z. Analysis of outpatient prescription indicators and trends in Chinese Jingzhou area between September 1 and 10, 2006-2009. Afr J Pharm Pharmacol. 2011;5(2):270-5.

13. Guyon AB, Barman A, Ahmed JU, Ahmed AU, Alam MS. A baseline survey on use of drugs at the primary health care level in Bangladesh. Bull World Health Organ. 1994;72(2):265-71.

14. Tamuno I, Fadare JO. Drug prescription pattern in Nigerian tertiary hospital. Trop J Pharm Res. 2012;11(1):146-52.

15. Memon K. Use of drugs in Sind province, Pakistan primary health care facilities, 2001. Available at: http://www.dcc2.bumc.bu.edu/prdu/other_Douments /khalil_concentration_paper.htm. Accessed on 27 August 2019.

Cite this article as: Kumari A, Kumar K, Gari M, Pallavi K, Choudhury S. A prospective observational study of prescription pattern in a tertiary care teaching hospital of Jharkhand. Int J Basic Clin Pharmacol 2019;8:2620-4. 